\title{
LIDERANÇA: ESTILOS E INFLUÊNCIAS NA PRODUTIVIDADE DAS ORGANIZAÇÕES
}

\author{
https://dx.doi.org/10.48097/2674-8673.2021n4p10
}

\author{
Alana Leite Paes ${ }^{1}$ \\ Alexsandro Costa da Silva ${ }^{2}$ \\ Arandi Maciel Campelo ${ }^{3}$ \\ João Pereira Dutra ${ }^{4}$
}

\begin{abstract}
RESUMO
O objeto de estudo deste artigo consiste nas análises dos estilos de liderança aplicadas no dia a dia das organizações. O estudo teve como objetivo identificar pontos negativos e positivos em cargos de liderança e como isso reflete diretamente nos liderados, a partir das definições estabelecidas por Chiavenato (2005). A pesquisa, bibliográfica, teve como fonte livros e artigos publicados na internet, em torno do tema central do artigo. $\mathrm{O}$ estudo revelou que os líderes utilizam as três formas de liderança para gerir suas equipes. A liderança autocrata, que geralmente não é muito eficaz; a liderança democrática, que tem os pontos positivos, mas requer muita habilidade do líder em conduzir a sua equipe; e a liderança liberal. O estudo revela como as atitudes e cada decisão tomada pelo líder afeta diretamente a conduta dos liderados, nos mostrando que no ambiente de trabalho a falta de um líder acarreta consequências que podem afetar o resultado de um setor ou de toda a empresa.
\end{abstract}

Palavras-chave: Liderança autocrata. Liderança liberal. Liderança democrática. Influências dos líderes.

Data de submissão: $13 / 10 / 2020$

Data de aprovação: 17/11/2020

\begin{abstract}
The object of study of this article consists of the analysis of the leadership styles applied in the day to day of the organizations. The study aimed to identify negative and positive points in leadership positions and how this reflects directly on the followers, based on the definitions established by Chiavenato (2005). The research, of bibliographic character, had as source

\footnotetext{
1 Discente do curso de Administração da Faculdade Metropolitana da Grande Recife. Assistente Administrativa Trade Marketing e eventos regionais na Solar Br Coca-Cola. E-mail: alanalpaes@gmail.com

2 Discente do curso de Administração da Faculdade Metropolitana da Grande Recife.

E-mail: leque-costa@hotmail.com

3 Orientador. Doutor em Educação - Universidade Federal de Pernambuco; Administrador - Universidade de Pernambuco - FCAP/UPE; Mestre em Planificación y Gestion Organizacional - Universidad Autonoma de Madrid/Espanha; Mestre em Dirección y organización de Hospitales y Servicios de Salud - Universidad Politécnica de Valencia/Espanha; Especialista em Marketing - FCAP/UPE; Consultor em sistemas organizacionais desde 1984; Professor e Diretor acadêmico da faculdade Metropolitana da Grande Recife.

E-mail: arandi.campelo@globo.com

4 Discente do curso de Administração da Faculdade Metropolitana da Grande Recife.

E-mail: Joaopdutra@hotmail.com
} 
books and articles published in the internet, around the central theme of the article. The study revealed that leaders use the three forms of leadership to manage their team. Autocratic leadership, which is generally not very effective; democratic leadership, which has the good points, but requires a lot of skill from the leader to lead his team; and liberal leadership. The study reveals how the attitudes and each decision taken by the leader directly affects the conduct of the followers, showing us that in the work environment the lack of a leader has consequences that can affect the results of an industry or the entire company.

Keywords: Autocratic leadership. Liberal leadership. Democratic leadership. Influences of leaders.

\section{INTRODUÇÃO}

Em linhas gerais esta pesquisa aborda o tema da liderança, dos estilos e das influências na produtividade das organizações. O objetivo da escolha desse assunto será destacar a importância do líder no ambiente de trabalho em uma organização e sua influência sobre os liderados. Hoje, a capacitação profissional e engajamento entre líderes e liderados revelam muito sobre os resultados encontrados no ambiente de trabalho. A busca constante de desempenho que vemos no mercado tornou a questão da liderança dentro das organizações uma discussão essencial. Com isso, os verdadeiros líderes devem procurar estar à frente de projetos que venham gerar mudanças significativas.

\section{REFERENCIAL TEÓRICO}

Foram abordadas as principais bases conceituais sobre estilos de liderança, influências dos líderes sobre o desempenho dos liderados e clima organizacional, focados no tema central do artigo. Por conta da pandemia da Covid-19 a pesquisa de campo não pôde ser realizada, ficando limitada à pesquisa bibliográfica. Assim, formaram as bases deste artigo os trabalhos de Chiavenato (2003; 2005), Caravantes (2005), Bennis (1988), Hunter (2004) e Drucker (1996), além da colaboração de outros autores não menos importantes, destacados nas referências deste artigo.

\section{ESTILOS DE LIDERANÇA}

Chiavenato (2003, p. 124) afirma que as teorias sobre estilos de liderança podem ser definidas como "[...] teorias que estudam a liderança em termos de estilos de comportamento do líder em relação aos seus subordinados. A abordagem dos estilos de liderança se refere àquilo que o líder faz, isto é, o seu comportamento de liderar". White e Lippitt (2000) 
consideravam que os estudos sobre liderança deveriam detectar o tipo de comportamento que identifica os estilos exercidos pelos líderes.

Chiavenato (2005), Vergara (2007) e Maximiano (2008) reforçam os estilos de liderança que foram a base dos estudos dos dois pesquisadores citados. Todavia, Chiavenato (2005) apresenta informações detalhadas desses estudos e os define da seguinte maneira:

Liderança autocrática: o líder procura promover sua autoimagem por meio do autoritarismo nas decisões, sem considerar as opiniões de seus liderados. O que ele espera é que suas decisões sejam seguidas cegamente. As tarefas realizadas pelos liderados, na maioria das vezes, são sobre pressão, mostrando assim sinais de tensão, frustração e agressividade.

Liderança liberal: o líder deixa a decisão para a equipe. Ele só se manifesta quando solicitado. Seu comportamento frente aos liderados é sutil e sem firmeza e as tarefas exercidas não são a contento quanto à qualidade e à quantidade, levando os liderados a demonstrarem sinais de individualismo, agressividade, insatisfação. Este é um estilo que, dependendo das circunstâncias ao qual será aplicado e do grau de maturidade dos liderados, poderá surtir resultados negativos, pois o líder não obtém o respeito da equipe e suas decisões podem ser ignoradas por ter dado grande abertura para decisões individuais ou do grupo.

Liderança democrática: o líder procura ter a uniformidade entre o trabalho a ser realizado e a equipe, percebendo a necessidade de cada um, dando abertura para o diálogo do grupo por meio da comunicação, auxiliando na resolução de problemas, dando melhores soluções e sugerindo ideias. As tarefas são exercidas pelos liderados com satisfação, qualidade, comprometimento e responsabilidade, pois todos se sentem parte do objetivo a ser alcançado.

Na prática, o líder utiliza os três processos de liderança de acordo com a situação, com as pessoas e com a tarefa a ser executada. O líder tanto manda cumprir ordens, como consulta os subordinados antes de tomar uma decisão, como também sugere a algum subordinado realizar tarefas. Ele utiliza a liderança autocrática, a democrática e a liberal em várias circunstâncias.

Chiavenato (2003, p. 125), também afirma que "os grupos submetidos à liderança autocrática apresentaram maior quantidade de trabalho produzido. Sob a liderança liberal, não se saíram muito bem em relação à quantidade e qualidade. Com a liderança democrática, os grupos apresentaram um nível quantitativo equivalente à liderança autocrática”.

De acordo com Geraldo R. Caravantes:

Para cumprir as expectativas que as outras pessoas têm a seu respeito, os líderes devem enfrentar numerosos desafios. Em grande parte, o sucesso de qualquer líder 
depende de sua capacidade de cuidar desses desafios de uma maneira que as pessoas aceitem. Não obstante um número qualquer de desafios ser inerente a determinada situação, três são relativamente constantes: clientela múltipla, decisões as vezes impopulares e diversidade. (CARAVANTES, 2005, p. 506).

Amaru Maximiano (2011, p. 264) afirma que "todos podemos combinar diversos graus de autocracia e democracia em nossa maneira de lidar com funcionários e equipes".

$\mathrm{O}$ autor também afirma que "para ser eficaz, o estilo deve ser apropriado à situação. A eficácia do estilo de liderança é avaliada pelo efeito sobre o desempenho da tarefa e sobre a satisfação do liderado naquela ocasião". Para ser eficaz, o liderado deve se mostrar satisfeito e também ter um desempenho satisfatório. (MAXIMIANO, 2011, p. 266).

Adir Muniz (2007, p. 207) nos ensina que "não se pode considerar que exista um estilo de liderança que possa ser considerado o 'melhor' e que, portanto, passe a ser indistintamente recomendável". Tudo vai depender da situação da empresa e da situação em que o líder e os liderados são colocados no momento, pois não só o líder tem capacidade de mudar seu estilo como também seus liderados, de acordo com o estilo de liderança exercido pela sua chefia.

Dornelas (2007) e Chiavenato (2004) afirmam que em uma organização onde há centralização da gestão não são aceitas sugestões e as responsabilidades são atribuídas a um pequeno grupo.

\section{Influências do líder no desempenho dos liderados}

Se existe uma característica peculiar no processo de liderança, ela está na distinção entre mobilizar as outras pessoas a fazer e mobilizá-las para querer fazer. Os que ocupam cargos de autoridade podem levar os outros a fazer algo, devido ao poder que estes superiores possuem. Os líderes mobilizam os outros para que queiram agir graças à credibilidade de que dispõem. Há uma enorme diferença entre angariar apoio e dar ordens, entre conquistar compromisso e impor obediência. Os líderes mantêm a credibilidade em consequência de suas ações ao desafiar, inspirar, permitir, guiar e encorajar. (SILVA, 2010).

De acordo com Warren Bennis (1988), outros fatores que se destacam no momento de identificar uma liderança exemplar e que geralmente são exigidos de um líder, tanto pelos colaboradores, tanto pelos clientes são:

a) Direção e significado: o primeiro passo é dar direção e significado para a equipe. É importantíssimo que cada membro subordinado saiba e entenda para onde está se dirigindo e qual a sua contribuição produtiva para o alcance da meta definida. 
b) Confiança: o verdadeiro líder é aquele que passa confiança no âmbito da organização, criando, assim, um ambiente favorável e fortalecendo o comprometimento de respeito entre líder e colaboradores com o melhor aproveitamento de suas habilidades.

c) Otimismo: o otimismo é contagioso, se expandindo ao resto da organização. O líder otimista é uma pessoa que não teme as dificuldades, encarando os obstáculos como perfeitamente superáveis. Isto o leva a atuar com um nível de audácia que permite alcançar metas que uma pessoa pessimista não conseguiria atingir, ou seja, um líder otimista sabe criar uma cultura de trabalho positiva.

d) Busca de resultados: é fundamental que o líder tenha sempre a iniciativa de ajudar diretamente na busca de resultados almejados, contribuindo para a organização ser um ambiente sempre produtivo.

De acordo com Warren Bennis (1988), o verdadeiro líder é aquele que passa confiança no âmbito da organização, criando assim um ambiente favorável e fortalecendo o comprometimento de respeito entre líder e colaborador com o melhor aproveitamento de suas habilidades.

Contudo, se faz necessário destacar a diferença em gerenciar e gerir uma equipe. Ainda hoje, em plena era digital, encontramos muitos "gerentes" que passam a maior parte do tempo assinando documentos. Outros se orgulham da disciplina que impõe através do chicote. Ora, assim é fácil comandar e não há necessidade de qualquer treinamento gerencial ou graduação em Administração. Este modelo de chefia é aquele que vai atrás da equipe, empurrando o seu time. Se os colaboradores relatam alguma dificuldade na execução do trabalho ou alguma barreira por partes de outras gerências, ele costuma esquivar-se da responsabilidade. Ele é competente, claro, mas na arte de cobrar da equipe.

Embora as distâncias no mundo atual estejam de certa forma menores com a era digital, ainda assim está cada vez mais difícil contratar líderes eficazes, pois eles estão todos muito bem empregados, ocupados, ganhando salários altos, tornando-se mais difíceis de cobrir ofertas. É que um bom líder, ao contrário do antigo chefe, sai na frente da sua equipe, abrindo caminho e enfrentando as turbulências. Ele assume a responsabilidade pelos resultados e defende seus liderados.

O diferencial de um grande líder é saber que se for um bom líder será menos reconhecido que a sua equipe. No sucesso do resultado alcançado, os aplausos serão para os colaboradores e havendo fracasso absorverá a crítica, solitário. 
Um bom líder vivencia situações em que o colaborador se sente magoado com as suas críticas no momento, mas o colaborador o agradecerá no futuro por aquele aprendizado. $\mathrm{O}$ bom líder trabalha incessantemente para o sucesso dos colaboradores, pois sabe que só assim o seu sucesso virá. Ser um líder contemporâneo é garantia de trabalho neste mundo moderno e para isso é necessário sinergia com a equipe.

Dessa forma, torna-se mais fácil aplicar alguns pontos importantes nas funções de um líder influenciador. Segundo González (1996), o líder de uma equipe efetiva: a) articula uma visão, cria uma missão clara, desenvolve metas, objetivos e planos de ação; b) tem capacidade para envolver os membros da equipe; c) assegura o cumprimento das tarefas e a conveniente atribuição do trabalho; d) é capaz de inspirar um desejo de produzir produtos e serviços de alta qualidade; e) tem habilidade de comunicar-se com todos os membros da equipe e de estabelecer relações com importantes membros fora da equipe; f) é hábil em sua atitude de escuta, em resolver conflitos e em construir consenso; g) é capaz de criar um ambiente aberto onde os membros expressem livremente suas visões e opiniões.

\section{As influências do líder no ambiente de trabalho}

Segundo Spector (2006, p. 494), “a ideia comum que se faz parte de várias definições diz que liderança envolve influenciar as atitudes, crenças, comportamentos e sentimentos de outras pessoas". Para o autor, os líderes estão frequentemente associados a cargos de supervisão, porém, ser um supervisor não garante que seja capaz de influenciar os outros.

Para Bergamini (1997), o líder caracteriza-se:

Por uma forte busca de responsabilidade e perfeição na tarefa, vigor e persistência na perseguição dos objetivos, arrojo e originalidade na resolução de problemas, impulso para o exercício da iniciativa nas situações sociais, autoconfiança e senso de identidade pessoal, desejo de aceitar as consequências da decisão e ação, prontidão para absorver o stress interpessoal, boa vontade em tolerar frustrações e atrasos, habilidade para influenciar o comportamento de outras pessoas e capacidade de estruturar os sistemas de interação social no sentido dos objetivos em jogo. (BERGAMINI, 1997 p. 31).

Na abordagem de Hunter (2004, p. 47), “um líder é uma pessoa que unifica e atende as necessidades reais de seus comandados e remove todos os empecilhos para que possam servir”. Dessa forma, o líder deverá possuir habilidade e liderança para influenciar pessoas a trabalharem motivadas, com enorme entusiasmo, visando, assim, atingir os objetivos identificados para o bem comum dos seus colaboradores.

Ainda, segundo Hunter (2004, p. 25), "liderança é a habilidade de influenciar pessoas para trabalharem entusiasticamente, visando atingir os objetivos identificados como sendo para o bem comum". 
Conforme cita Drucker (1996, p. 194), “o líder tem que gerenciar a si próprio; conhecer as suas forças e colocá-las em benefício dos bons propósitos. A liderança começa, não quando você estabelece regras para os outros, mas quando você traça regras muito exigentes para si próprio".

Para Lacombe e Heiborn (2003, p. 347), “um líder não é um gerente no sentido natural. Líder é alguém que os outros avaliam como o cardinal responsável pela concretização dos objetivos do grupo".

Outro fator importante ao líder é crer no potencial de cada funcionário de sua equipe. Acreditar que cada cooperador, independentemente de seu cargo ou função, possa desenvolver um bom trabalho. O líder precisa enaltecer e incentivar quando algum colaborador cumpre eficazmente alguma atividade, podendo assim motivá-lo ainda mais e impulsioná-lo a executar suas tarefas com maior eficácia e maestria: "uma das centrais características de um bom administrador é sua desenvoltura em lidar com gente, pois os efeitos conseguidos são fruto do trabalho e dos esforços das pessoas que ele coordena e supervisiona". (LACOMBE; HEILBORN, 2003).

O reconhecimento de um trabalho bem feito desperta em quem o aufere a percepção de dever cumprido e de satisfação, favorecendo para que surjam menos conflitos no ambiente de trabalho.

De acordo com Cusins (1994, p. 9), “[...] a gerência assume o papel de direcionar e conjugar esforços, comunicar, liderar, motivar, avaliar e recompensar as pessoas dentro da organização".

Diante do processo de globalização as empresas vêm buscando cada vez mais se aperfeiçoar no mercado. Um ambiente de trabalho é formado por profissionais qualificados, competentes e satisfeitos. Por isso, é preciso que o líder aja com a razão e não somente com a emoção e que permeie as relações de trabalho, requerendo parceria, cooperação, polidez e respeito.

A falta de um líder pode acarretar ameaças para qualquer organização devido à competitividade. Os líderes têm que buscar novos caminhos e fazer com que as coisas aconteçam. Daí a necessidade de aprendizagem das virtudes nas relações de trabalho, de forma que o afeto possa emergir e mostrar sua capacidade de melhorar as relações interpessoais.

No entanto, para que isso possa acontecer é preciso que o líder tenha "humildade para lidar com o poder e prudência para definir rumos de vida a quem trabalha e produz". (BOM SUCESSO, 2002, p. 11). 
O processo de liderança é um caminho e não um produto acabado. Não existem fórmulas mágicas e rápidas para transformar uma organização ou mudar uma postura de liderança. No entanto, o caminho está no desenvolvimento dos talentos e da criatividade de cada profissional.

\section{METODOLOGIA}

Por conta da pandemia da Covid-19 a pesquisa de campo não pôde ser realizada, ficando limitada à pesquisa bibliográfica. Assim, formaram as bases deste artigo os trabalhos de Chiavenato (2003; 2005), Caravantes (2005), Bennis (1988), Hunter (2004) e Drucker (1996).

Este artigo está centrado na temática sobre liderança, estilos e influências nas organizações. Desta forma, visando analisar o comportamento dos líderes perante os liderados, observando se tem reações negativas ou positivas na produtividade e no clima do ambiente de trabalho, analisando, assim, se as atitudes dos líderes geram resultados positivos ou negativos do ponto de vista da empresa.

A escolha do tema foi motivada pela importância da necessidade da existência de uma liderança em qualquer atividade realizada por um colaborador a fim de obter melhor retorno na qualidade do serviço prestado pelo mesmo.

Este trabalho tem como objetivo apontar a importância da forma em que um líder exerce sua liderança e mostrar que ambas as partes, dependendo da situação em que se encontram, podem mudar seu comportamento e atitude perante uma situação no ambiente de trabalho.

Através de um estudo descritivo, foi utilizado o método qualitativo para apresentar, de forma coerente, uma análise acerca da identificação da postura do líder e suas consequências, levando em consideração uma pesquisa bibliográfica baseada nas obras de Chiavenato e Maximiano, além de citações encontradas em livros e sites.

O propósito levou em consideração analisar a realidade do ambiente de trabalho das organizações, no que se refere à harmonia entre os colaboradores durante a jornada de trabalho, sendo usada para a melhora da produtividade e resultados sustentáveis.

\section{CONSIDERAÇÕES FINAIS}

O tema abordado neste artigo busca entender o ambiente de trabalho como um todo, começando com a liderança, a partir das atitudes de um líder identificado pela forma que exerce sobre os colaboradores, influenciando-os em suas performances, mostrando a importância da liderança correta e explicando que as decisões do líder são fundamentais para o resultado da equipe. 
Os vários autores citados neste artigo mostram que maneiras de gerir e liderar equipes são fundamentais para os resultados e de um excelente ambiente de trabalho. Algumas atitudes e decisões são fundamentais para que a empresa e, consequentemente, a equipe, tenham bom desempenho.

Em muitas organizações observamos que quando seus líderes não atuam em conformidade com a cultura organizacional os resultados são os mais variados possíveis, resultando no fato de algumas equipes obterem melhores resultados que outras dentro da mesma instituição. Muitas vezes os insucessos são atribuídos aos subordinados, mas quase sempre estão relacionados à maneira de liderar suas equipes.

Percebemos que, além das três formas de liderar que abordamos neste artigo, não há uma linha exata de liderança e sim uma fusão entre as formas, adaptadas a cada situação, equipe e às culturas organizacionais.

\section{REFERÊNCIAS}

BENNIS, Warren. Liderança e gestão de pessoas. In: HSM Management. São Paulo: Publifolha, 2002.

BERGAMINI, C. W. Psicologia Aplicada a Administração de Empresas. 4. ed. São Paulo: Atlas, 2006.

BOM SUCESSO, Edina de Paula. Relações interpessoais e qualidade de vida no trabalho. Rio de Janeiro: Qualitymark, 2002.

CARAVANTES, Geraldo R.; CARAVANTES, Claudia B.; KLOECNER, Monica C. Administração: teorias e processos. São Paulo: Pearson Prentice Hall, 2005.

CHIAVENATO, Idalberto. Introdução à teoria geral da administração: uma visão abrangente da moderna administração das organizações. 7. ed. rev. e atual. Rio de Janeiro: Elsevier, 2003.

DRUCKER, Peter F. O líder do futuro. São Paulo: Futura, 1996.

HUNTER, James C. O monge e o executivo: uma historia sobre a essência da liderança. Rio de Janeiro: Sextante, 1998.

LACOMBE, Francisco José M.; HEILBORN, Gilberto Luiz J. Administração: princípios e tendências. São Paulo: Saraiva, 2003.

MAXIMIANO, Antonio Cesar Amaru. Introdução à Administração. 8. ed. Rev. e ampl. São Paulo: Atlas, 2011.

MUNIZ, Adir Jaime de Oliveira; FARIA, Hermínio Augusto. Teoria geral da Administração: 5. ed. rev. e ampl. São Paulo: Atlas, 2007. 
SPACTOR, Paul E. Psicologia nas organizações. 2. ed. São Paulo: Saraiva, 2006. 